\title{
The Reliability of Flexor Hallucis Longus Stretch Test in Subjects with Asymmetric Hallux Valgus Angles
}

\author{
Eun-Kyung Koh'1, Do-Young Jung²
}

'Department of Physical Therapy, Masan University, Changwon; 2Department of Physical Therapy, Kinesiopathologic Science Institute, Joongbu University, Geumsan-gun, Changcheongnam-do, Korea

Purpose: The flexor hallucis longus stretch test can determine the shortness of the flexor hallucis longus muscle by measuring the angle of extension in the first metatarsophalangeal (MTP) joint at maximum ankle dorsiflexion. Less than 30 degrees of the first MTP joint at the maximal ankle dorsiflexion indicates shortness of the flexor hallucis longus muscle. The purpose of this study was to examine the intra- and inter-reliability of the flexor hallucis longus stretch test in subjects with asymmetric hallux valgus (HV) angles.

Methods: Sixteen subjects with asymmetric HV angles participated in this study. In sitting position, dorsiflexion angles of the first MTP joint were measured with maximum ankle dorsiflexion on each side. ICC $(3,1)$ and ICC $(3, \mathrm{k})$ models were used, respectively, to assess the intra-reliability and inter-reliability of the flexor hallucis longus stretch test. The paired-t test was used to compare the dorsiflexion angle of the first MTP joint on the side with the smaller HV angle with that of the side with the larger HV angle.

Results: The results of the study showed that both intra- and inter-reliability were more than 0.95 of the coefficient. Dorsiflexion angle of the first MTP joint was higher on the side with the smaller HV angle.

Conclusion: Use of the flexor hallucis longus stretch test is acceptable in clinical settings because both intra- and inter-reliability were high in subjects with asymmetric HV angles. In addition, shortness of the flexor hallucis longus muscle is associated with HV angle. This study provides useful information for use in management of HV deformity.

Keywords: First metatarsophalangeal joint, Flexor hallucis longus stretch test, Hallux Valgus

\section{서 론}

기능적으로 발허리발가락관절(metatarsophalangeal joints)의 주요한 움직임은 발등굽힘이다. 보행 중 추진기 시 발허리발가락관절의 적절 한 발등굽힘은 발바닥굽힘근들 작용에 의해 몸을 앞쪽으로 추진시 킴으로써 발허리발가락관절의 축을 중심으로 뒷발이 앞발을 타고 넘어가게 한다. 또한 발허리발가락관절의 발등굽힘은 권양기 기전 (windlass mechanism)으로 발바닥널힘줄(plantar aponurosis)을 신장시 켜, 아치를 높여주고, 발꿈치 떼기 동안에 발을 견고하게 만드는 것을 도와준다. ${ }^{2}$

보행 시 엄지 발허리발가락관절은 시상면에 대해 상당한 가동범 위를 지니고 있다. 보행 동안에 필요한 엄지 발허리발가락관절의 운 동범위는 30-40 라고 보고되었다.,3 Nawoczenski 등 ${ }^{3}$ 은 전자기 3차원 동작분석기를 이용해 정상 보행 시 엄지 발허리발가락관절의 발등 굽힘 각을 측정한 결과 평균 $42^{\circ}$ 라고 보고하였으며 Hopson 등은 정

Received Mar 22, 2016 Revised Apr 22, 2016

Accepted Apr 23, 2016

Corresponding author Do-Young Jung

E-mail ptsports@joongbu.ac.kr
상보행을 위해서는 엄지 발허리발가락관절의 발등굽힘 각이 약 $65^{\circ}$ 가 요구된다고 보고하였다. 기능적 엄지 제한증(functional hallux limitus)은 비체중지지 검사 시 엄지 발허리발가락관절이 정상적인 관절 가동범위를 갖더라도 보행 중 엄지 발허리발가락관절의 발등굽힘 각이 감소한다. ${ }^{4}$ 엄지 발허리발가락관절의 발등굽힘 부족은 정상적 인 타고 넘기(roll-over) 패턴을 방해함으로 체중이 엄지의 가쪽 또는 안쪽으로 이동하게 되는데 엄지 가쪽으로의 체중 이동은 둘째 혹은 셋째 발허리머리에 힘이 증가되어 발허리발가락관절에 통증을 유발 시키는 반면 엄지 안쪽으로의 체중 이동은 몸쪽 발가락뼈에서 벌림 력(hallux valgus force)을 증가시켜 발허리발가락관절의 내측에 통증 을 일으킨다.56 하지만 아직까지 엄지발가락가쪽휨증(hallux valgus) 정도에 따라 엄지 발허리 발가락관절의 발등굽힘 각을 비교한 연구 는 없는 실정이다.

엄지 발허리발가락관절의 발등굽힘 각도 제한은 긴허리굽힘근 (flexor halluces longus, FHL)과 발바닥널힘줄(plantar aponeurosis)의 단

Copylight (C2016 The Korea Society of Physical Therapy

This is an Open Access article distribute under the terms of the Creative Commons Attribution Non-commercial License (Http:// creativecommons.org/license/by-nc/3.o.) which permits unrestricted non-commercial use, distribution, and reproduction in any medium, provided the original work is properly cited. 
축 또는 관절의 제한에 의해 야기될 수 있다. 이론적으로, 긴엄지굽힘 근의 길이 검사는 발목관절을 발등굽힘(긴엄지굽힘근 신장된 상태) 과 발바닥쪽굽힘(긴엄지굽힘근의 느슨한 상태) 시 발허리발가락관 절의 발등굽힘 관절가동범위를 비교함으로써 결정할 수 있다. 긴엄 지굽힘근 스트레치 검사(FHL stretch test)를 처음으로 언급한 Michelson과 Dunn ${ }^{7}$ 은 발목관절 발등굽힘 시 엄지 발허리발가락관절의 발 등굽힘 각이 $20^{\circ}$ 이하면 긴엄지굽힘근의 길이가 제한된 것이라고 하 면서 이러한 긴엄지굽힘근의 제한된 가동역(excursion)은 엄지강직증 (hallux rigidus)의 원인이라고 하였다. Sharman은 발목관절 발바닥쪽 굽힘 상태에서 엄지 발허리발가락관절 발등굽힘이 $30^{\circ}$ 이상이고 발 목관절 발등굽힘 상태에서 엄지 발허리발가락관절 발등굽힘이 $30^{\circ}$ 이하이면 긴엄지굽힘근이 단축된 것이라 기술하였다. 비록 이전 문헌 들에서 긴엄지굽힘근 단축 검사시 엄지 발허리발가락관절의 발등굽 힘 각의 기준값이 차이는 있지만 아직까지 긴엄지굽힘근 길이 검사 에 대한 신뢰도 검사에 대한 연구는 없는 실정이다. 따라서 본 연구에 서는 비대칭적인 엄지발가락가쪽휨 각을 갖는 대상자들에서 긴엄지 굽힘근 스트레치 검사에 대한 신뢰도를 알아보고자 하였다.

\section{연구방법}

\section{1. 연구대상}

본 연구에서는 좌·우 발의 엄지발가락가쪽휨증 각이 5 도 이상 차이

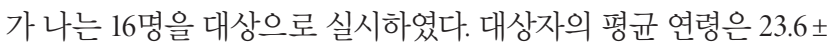
3.2 세, 신장은 $165.3 \pm 6.9 \mathrm{~cm}$ 그리고 체중은 $60.2 \pm 12.5 \mathrm{~kg}$ 이었다. 발목 및 발의 병리학적 증상이 있거나 하지의 정형외과 수술 및 당뇨, 신경 병, 관절염이 있는 대상자 및 발의 피부 또는 발톱 손상이 있는 경우 는 제외하였다. 모든 대상자들에게 실험 전 실험 동의서의 내용을 알 려주고 연구 참여에 동의를 얻은 후에 실시하였다.

\section{2. 실험방법}

1) 측정도구

엄지 발허리발가락관절의 발등굽힘 각도를 측정하기 위해 플라스틱 각도측정계(plastic goniometer, Baseline, USA)를 사용하였다. 짧은 엄 지발가락 때문에 $12 \mathrm{~cm}$ 길이의 플라스틱 각도측정계는 엄지 발허리 발가락관절의 각도측정을 위해 기존 플라스틱 각도측정계를 $6 \mathrm{~cm}$ 길 이로 절단하여 사용하였다. 각도측정계의 주 눈금은 $2^{\circ}$ 단위로 표시 되어있고 보조 눈금은 $1^{\circ}$ 단위로 표시되어 있다.

\section{2) 실험절차}

엄지 발허리발가락관절의 수동 발등굽힘 각도는 측정자 내 그리고 측정자 간 신뢰도를 측정하기 위해 두 명의 측정자와 두 명의 보조자

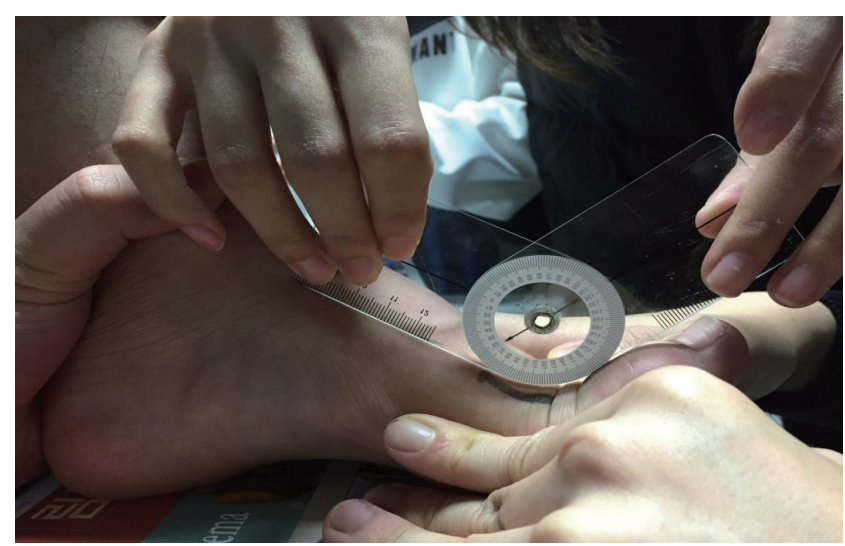

Figure 1. The measurement of dorsiflexion angle of the first metatarsophalangeal joint.

가 선택되었다. 측정방법에 대해 측정자에게 설명하였고 관절의 위 치, 뼈 표식점의 식별, 관절각도측정계 사용 시 미숙함을 예방하도록 한 달 간 연습하였으며 본 실험 전 15 명의 예비실험을 실시하였다.

측정하기 전에 비대칭적인 엄지발가락가쪽휨증 각을 지닌 좌·우 발의 엄지 발허리뼈와 엄지 발가락뼈의 등쪽 중앙에 선을 각각 그었 다. 수동적으로 엄지발가락뼈를 모음하여 두 개의 선이 일치된 상태 에서 엄지 발허리발가락관절의 발등굽힘 각을 측정하였다.

엄지 발허리발가락관절의 발등굽힘 각도 측정을 위해 정적 부분 체중지지 상태에서 의자 끝에 앉도록 하였고 측정자는 의자의 높이 를 조절하면서 발목의 최대 발등굽힘이 되도록 발을 의자 뒤로 혹은 앞으로 내밀었다. 발목관절의 최대 발등굽힘 기준은 뒤꿈치가 바닥 에 떨어지기 직전으로 하였으며 측정자가 수동으로 끝느낌이 단단함 (firm)이 있을 때까지 몸쪽 발가락뼈를 잡고 엄지 발허리발가락관절 을 발등굽힘하도록 하였다(Figure 1).

측정자는 관절각도계의 중앙 지점(fulcrum)이 엄지 발허리발가락 관절의 발등 쪽에 위치하도록 하였다. 엄지 발허리뼈의 등쪽 중간 선 을 통해 고정 팔을 정렬시켰고 엄지 발가락뼈 등쪽 중간선 위에 움직 임 팔을 정렬시켰다(Figure 1). 측정 보조자는 발목관절의 최대 발등 굽힘 시 수동적인 발허리발가락관절의 각도를 각각 3 번 반복하여 읽 고 기록하였다. 보조자가 기록한 각도는 측정자가 알지 못하도록 하 였고 다음 번 측정자와 보조자는 동일한 방법으로 다른 장소에서 측 정하였다. 측정 발의 순서와 측정자 순서는 무작위로 실시하였다.

\section{3) 통계방법}

측정자 내 그리고 측정자 간 신뢰도를 구하기 위해 급간 내 상관계수 (Intraclass Correlation Coefficient, ICC) (3,1)과 (3,k) 모델을 각각 이용하 여 발목의 발등굽힘 시 엄지 발허리발가락의 폄 각도와 발바닥 굽힘 시 엄지 발허리발가락관절을 발등굽힘 각도에 대해 상관계수(coeffi- 
Table 1. Intrarater reliability of flexor halluces longus stretch test

\begin{tabular}{lcc}
\hline \multirow{2}{*}{ Side } & Rater 1 & Rater 2 \\
\cline { 2 - 3 } & ICC $(95 \% \mathrm{Cl})$ & ICC $(95 \% \mathrm{Cl})$ \\
\hline Less HV angle & $0.99(0.97-0.99)$ & $0.99(0.97-0.99)$ \\
More HV angle & $0.99(0.97-0.99)$ & $0.99(0.97-0.99)$ \\
\hline
\end{tabular}

Table 2. Interrater reliability reliability of flexor halluces longus stretch test

\begin{tabular}{lll}
\hline Side & \multicolumn{1}{c}{$\mathrm{ICC}_{\text {single }}(95 \% \mathrm{Cl})$} & \multicolumn{1}{c}{$\mathrm{ICC}$ average $95 \% \mathrm{Cl}$} \\
\hline Less HV angle & $0.96(0.89-0.97)$ & $0.98(0.94-0.99)$ \\
More HV angle & $0.95(0.85-0.98)$ & $0.97(0.92-0.99)$
\end{tabular}

cient)를 구하였다. 상관계수에 대한 해석은 다음과 같다: >0.75는 매 우 높음, 0.4- 0.75 는 중간 내지 높음, 그리고 < 0.4 는 낮음을 의미한다. 비대칭적인 엄지발가락휨증 각이 심한 측좌 덜한 측의 발목의 최대 발등굽힘 시 엄지발허리발가락의 발등굽힘 각을 비교하기 위해 짝 비교 t-검정을 실시한다. 유의수준은 0.05 로 하였으며 통계 프로그램 은 SPSS version 17.0 (SPSS Inc., Chicago, IL, USA)을 이용하여 통계 처 리하였다.

\section{결 과}

엄지발가락휨증 각이 심한 측과 덜한 측 모두 발목관절의 최대 발등 굽힘 시 엄지 발허리발가락 관절의 발등굽힘 각도의 검사자 내 상관 계수는 검사자 1 과 검사자 2 는 각각 0.99 로 높은 신뢰도를 나타냈으며 (Table 1), 검사자 간 신뢰도 또한 단일 측정시와 3 번 반복측정한 평균 값으로 한 상관계수가 0.95 이상으로 높은 상관 관계를 보였다(Table 2). 발목관절의 최대 발바닥굽힘 시 엄지 발허리발가락관절의 발등 굽힘 각도는 엄지발가락휨증 각이 심한 측이 덜한 측보다 유의하게 작았다 $(\mathrm{p}<0.05)$ (Figure 2$)$.

\section{고 찰}

본 연구는 비대칭적인 엄지발가락휨 각이 있는 대상자에게 긴허리굽 힘근의 스트레치 검사 시 검사자 내와 검사자 간 신뢰도를 알아보고 자 하였다. 본 연구결과, 검사자 내와 검사자 간 신뢰도가 0.95 이상으 로 매우 높게 나왔다. 특히 검사자 간 신뢰도에서 단일 측정보다 3 번 반복측정한 값이 더 신뢰도가 높게 나왔으므로 임상에서는 반복측 정하여 평균값으로 긴허리굽힘근의 스트레치 검사를 실시하는 것을 추천한다. 몇몇 연구에서 엄지 발허리발가락관절의 발등굽힘 각에 대한 신뢰도를 검사하였다.1,3,89 Otter 등9은 검사자 내와 검사자 간 신 뢰도가 각각 0.81 과 0.70 이었고 Hopson 등은 바로 누운자세와 앉은 자세에서 측정자 내 신뢰도 모두 0.95 , 그리고 Jones and Curran ${ }^{8}$ 은 엄

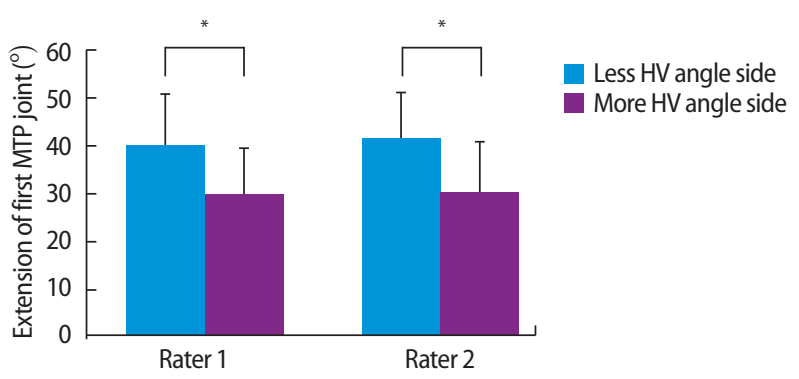

Figure 2. The difference in dorsiflexion of first MTP joint in less and more $\mathrm{HV}$ angle sides.

*Significant difference at $p=0.05$

지 발허리발가락관절의 발등굽힘 된 사진에 대해 각도계를 이용하 여 측정한 결과 초보자보다 경험 있는 측정자가 검사자 내와 검사자 간 신뢰도가 각각 0.95 와 0.97 로 더 높았다고 보고하였다. 본 연구에서 는 측정자에게 신뢰도 검사를 위해 관절의 위치, 뼈 표식점의 식별, 관절각도측정계 사용 시 미숙함을 예방하도록 한 달 간 연습하였으 며 본 실험 전 15 명의 예비실험을 실시하였다. 따라서 이전 연구와 마 찬가지로 본 연구에서도 긴허리굽힘근의 스트레치 검사 시 앉은 자 세에서 최대로 발목관절을 발등굽힘 한 상태에서 엄지 발허리발가 락관절의 발등굽힘 각 측정은 신뢰도가 매우 높았다.

본 연구에서는 비대칭적인 엄지발가락휨증 대상자의 심한 측과 덜 한 측간의 긴허리굽힘근의 스트레치 검사 시 심한 측이 덜한 측에 비 해 발목관절의 최대 발등굽힘 시 엄지 발허리발가락관절의 발등굽 힘 각이 유의하게 작았다. 이는 엄지발가락휨증 대상자의 심한 측이 덜한 측에 비해 긴허리굽힘근의 길이가 짧아졌음을 의미한다. Choi 등 ${ }^{10}$ 은 여성을 대상으로 무지외반각도와 엄지 발허리발가락관절의 제한이 유의한 상관관계를 가졌다고 보고하였지만 이 결과가 단지 관절의 제한 때문인지 아니면 근육의 짧아짐 때문인지에 대한 언급 은 하지 않았다. 긴허리굽힘근은 종아리뼈의 먼쪽 $2 / 3$ 와 빼사이막에 기시하여 발목관절이 먼쪽 엄지발가락뼈에 붙어 엄지 발허리발가락 관절을 지나간다. 긴허리굽힘근은 엄지발가락 굽힘, 발의 뒤침, 안쪽 세로활의 유지, 발뒤부의 안쪽번짐 토크와 발목관절의 발바닥 굽힘 토크를 생성하는 데 기여한다.1-14 또한 긴허리굽힘근은 추진기(pushoff)에 무게중심을 가속시키는 역할을 하는데 이때 발에 가해지는 힘 은 첫 번째 열(first ray)에서 가장 크며 엄지발가락에 체중의 $24 \%$ 그리 고 첫 번째 발허리발가락관절에 $29 \%$ 로 추정된다. ${ }^{15} \mathrm{Sharman}^{5}$ 은 엄지 발허리발가락관절의 발등굽힘 제한에 따른 보행 시 엄지 안쪽으로 의 체중 이동은 몸쪽 발가락뼈에서 벌림력(hallux valgus force)을 증가 시킨다고 언급하였다. 이전 문헌들에서 언급한 내용과 본 연구 결과 로 미루어 볼 때 엄지발가락휨증의 정도가 긴허리굽힘근의 단축과 관련 있으며 이는 보행 중 추진기 시 문제를 일으킬 수 있다. 따라서 엄지발가락휨증이 긴허리굽힘근의 단축과 관련있기 때문에 본 연구 
를 통해 엄지발가락휨증을 예방하고 관리하는 데 기초자료로 활용 될 수 있을 것이다.

본 연구는 몇 가지 제한점이 있다. 첫 번째로는 대상자 선정에 있어 서 엄지발가락휨증 기형진단명을 가지고 있는 대상자가 아니라 단지 비대칭적인 엄지발가락휨 각이 있는 있는 대상자로 하였다. 발목관 절 최대 발등굽힘 시 엄지 발허리발가락관절의 발등굽힘 각이 $\mathrm{Mi}-$ chelson과 Dunn ${ }^{7}$ 은 $20^{\circ}$ 이하 그리고 Sharman ${ }^{5}$ 은 $30^{\circ}$ 이하이면 긴엄지 굽힘근이 단축된 것이라 기술하였다. 본 연구에서는 엄지발가락이휨 증 각이 심한 쪽에서 엄지 발허리발가락관절의 발등굽힘 각이 한 명 의 측정자는 평균 $28.79^{\circ}$, 다른 한 명은 평균 $30.25^{\circ}$ 측정되었다. 이는 엄지발가락 휨증 기형이 심하지 않는 일반인들을 대상으로 측정하 였기 때문일 것으로 사료된다. 향후 연구에서는 엄지발가락휨증 기 형 군과 대조군을 대상으로 긴엄지굽힘근의 단축 정도를 알아볼 필 요가 있다. 두 번째 제한점으로 긴엄지굽힘근의 스트레치 검사에 대 한 타당도 검사이다. 발목의 최대 발등굽힘 자세에서 엄지 발허리발 가락관절의 발등굽힘은 발바닥널힘줄의 신장상태가 되기 때문에 이 로 인해 발허리발가락관절 동작을 제한할 수 있다. 따라서 향후 연구 에서 긴엄지굽힘근의 스트레치 검사에 대한 타당도를 알아볼 필요 가 있다.

결론적으로 본 연구는 비대칭적인 엄지발가락휨 각이 있는 대상 자에게 긴허리굽힘근의 스트레치 검사 시 검사자 내와 검사자 간 신 뢰도가 매우 높았으므로 임상적으로 측정방법에 대해 수용할 수 있 을 것이다. 또한 엄지발가락휨 각이 심한 쪽이 덜한 쪽에 비해 긴허리 굽힘근의 길이가 더 단축되었다. 이는 엄지발가락힘증 기형을 예방하 고 관리하는 데 유용한 정보로 활용될 수 있을 것이다.

\section{REFERENCES}

1. Hopson MM, McPoil TG, Comwall MW. Motion of the first metatarsophalangeal joint. Reliability and validity of four measurement tech- niques. J Am Podiatr Med Assoc. 1995;85(4):198-204.

2. Aquino A, Payne C. Function of the windlass mechanism in excessively pronated feet. J Am Podiatr Med Assoc. 2001; 91(5):245-50.

3. Nawoczenski DA, Baumhauer JF, Umberqer BR. Relationship between clinical measurements and motion of the first metatarsophalangeal joint during gait. J Bone Joint Surg Am. 1999;81(3):370-6.

4. Kappel-Bargas A, Woolf RD, Cornwall MW et al. The windlass mechanism during normal walking and passive first metatarsalphalangeal joint extension. Clin Biomech (Bristol, Avon). 1998;13(3):190-4.

5. Sharmann S. Movement system impairment syndromes of the extremities, cervical and thoracic spines. St. Louis, Mosby. 2010:445-6.

6. Yun SJ, Kang MH, Kim MH. Difference of position change of sesamoid bones during active abduction exercise of great toe in subjects with hallux valgus. J Kor Phys Ther. 2015;27(2):85-8.

7. Michelson J, Dunn L. Tenosynovitis of the flexor hallucis longus: a clinical study of the spectrum of presentation and treatment. Foot Ankle Int. 2005;26(4):291-303.

8. Jones AM, Curran SA. Intrarater and interrater reliability of first metatarsophalangeal joint dorsiflexion: Goniometry versus visual estimation. J Am Podiatr Med Assoc. 2012;102(4): 290-8.

9. Otter SJ, Aqalliu B, Baer N et al. The reliability of a smartphone goniometer application compared with a traditional goniometer for measuring first metatarsophalangeal joint dorsiflexion. J Foot Ankle Res. 2015;8:30.

10. Choi GH, Park KY, Byun SJ, et al. A study on angular correlation between hallux valgus and 1st MPJ dorsi-flexion according to work type and age of woman. J Kor Phys Ther. 2011;23(5):57-63.

11. Ferris L, Sharkey NA, Smith TS et al. Influence of extrinsic plantar flexors on forefoot loading during heel rise. Foot Ankle Int. 1995;16(8): 46473.

12. Thordarson DB, Schmotzer H, Chon J et al. Dynamic support of the human longitudinal arch. A biomechanical evaluation. Clin Orthop Relat Res. 1995;316:165-72.

13. Hintermann B, Nigg BM, Sommer C. Foot movement and tendon excursion: an in vitro study. Foot Ankle Int. 1994;15(7):386-95.

14. Klein P, Mattys S, Rooze M. Moment arm length variations of selected muscles acting on talocrural and subtalar joints during movement: An in vitro study. J Biomech. 1996;29(1):21-30.

15. Jacob HA. Forces acting in the forefoot during normal gait--an estimate. Clin Biomech (Bristol, Avon). 2001;16(9):783-92. 